\title{
FILTER ADAPTIF GPS PADA SISTEM DOWNLINK DATA
}

\author{
Agus Basukesti ${ }^{1}$, Bangga Dirgantara Adiputra ${ }^{2}$ \\ ${ }^{1}$ Prodi Teknik Elektro, ${ }^{2}$ Prodi Teknik Penerbangan \\ Sekolah Tinggi Teknologi Adisutjipto
}

\begin{abstract}
GPS (Global Positioning System) is a system used for navigation and positioning with the help of 32 satellites that orbit the earth. GPS satellites emit radio waves to activate the GPS receiver on the Earth to determine the exact location, speed and time for all weather conditions. Currently, GPS has a vital role in navigation drone. However GPS have a lot of noise, it is necessary to overcome the noise filter on the GPS. In this research conducted a simulation of adaptive algorithm in extracting data from the GPS sensor. The method in this research is the Kalman Filter. From the identification and simulation can be concluded that the adaptive algorithm is designed to work well and need to be implemented on the downlink system. The simulation results showed that the error of algorithm has convergent properties are increasingly shrinking.
\end{abstract}

Keywords: Adaptif, Kalman'filter, Antena

\begin{abstract}
Abstrak
GPS (Global Positioning System) adalah sebuah sistem yang digunakan untuk navigasi dan posisi dengan bantuan 32 satelit yang mengitari bumi. Satelit GPS memancarkan gelombang radio untuk mengaktifkan receiver GPS yang ada di bumi untuk menentukan lokasi yang tepat, kecepatan dan waktu untuk semua kondisi cuaca. GPS saat ini memiliki peran yang cukup vital dalam navigasi pesawat tanpa awak. Akan tetapi GPS memiliki banyak noise sehingga diperlukan filter untuk mengatasi noise pada GPS. Dalam penelitian ini dilakukan sebuah simulasi algoritma adaptif dalam mengekstrak data dari sensor GPS. Metode yang digunakan adalah kalman filter. Dari hasil identifikasi dan simulasi yang dilakukan dapat disimpulkan bahwa algoritma adaptif yang dirancang dapat bekerja dengan baik dan perlu diimplementasikan pada sistem downlink yang dirancang. Dari hasil simulasi didapatkan bahwa error dari argoritma memiliki sifat konvergen yaitu semakin lama semakin mengecil.
\end{abstract}

Kata kunci: Adaptif, Kalman filter, Antenna

\section{Pendahuluan}

GPS (Global Positioning System) adalah sebuah sistem yang digunakan untuk navigasi dan posisi dengan bantuan 32 satelit yang mengitari bumi. Satelit GPS memancarkan gelombang radio untuk mengaktifkan receiver GPS yang ada di bumi untuk menentukan lokasi yang tepat, kecepatan dan waktu untuk semua kondisi cuaca. GPS saat ini memiliki peran yang cukup vital dalam navigasi pesawat tanpa awak. Akan tetapi GPS memiliki banyak noise sehingga diperlukan filter untuk mengatasi noise pada GPS. Penelitian untuk menangani noise pada GPS telah dilakukan sebelumya (J. W. Chaffee dan J. S. Abel, 1992; C. Hide dkk, 2004; X. Mao dkk, 2002; I. M. Taylor dan M. A. Labrador, 2011; L. Wu dkk, 2011; S. Yamaguchi dan T. Tanaka, 2006; M. Zahaby dkk, 2009). 
Dalam penelitan sebelumnya, telah dilakukan aplikasi algoritma adaptif untuk mengatasi gangguan pada GPS. Salah satu algoritma yang banyak digunakan adalah kalman fiter. Dalam penelitian ini dilakukan sebuah simulasi kalman filter dalam pengantisipasi noise pada GPS navigasi. Penelitian ini cukup penting karena sistem downlink memerlukan informasi yang akurat untuk menentukan posisi dari target sehingga antena dapat diarahkan dengan baik. Antena Yagi merupakan antena jenis pengarah. Berkas Antena Yagi yang sempurna hanya akan mempunyai main lobe (Cuping Utama). Pembuatan antena yang sempurna sangat sulit, sehingga keberadaan side lobe dan back lobe dapat dimaklumi. Dengan mengarahkan Antena Yagi kearah target diharapkan komunikasi target dengan ground station dapat berjalan dengan baik.

\section{Metode}

Pemodelan gerak navigasi sebuah pesawat cukup penting untuk dilakukan dalam mendesain sebuah algoritma adaptif. Persamaan yang digunakan dalam perancangan ini adalah:

$$
\begin{aligned}
& x=x_{0}+v_{x} \cdot t \\
& y=y_{0}+v_{y} \cdot t \\
& v_{x}=v_{x_{0}}+a_{x} \cdot t \\
& v_{y}=v_{y_{0}}+a_{y} \cdot t
\end{aligned}
$$

Persamaan tersebut kemudian diubah ke bentuk state space menjadi

$$
\begin{aligned}
& {\left[\begin{array}{l}
x_{(k)} \\
y_{(k)} \\
v_{x(k)} \\
v_{y_{(k)}}
\end{array}\right]=\left[\begin{array}{llll}
1 & 0 & 1 & 0 \\
0 & 1 & 0 & 1 \\
0 & 0 & 1 & 0 \\
0 & 0 & 0 & 1
\end{array}\right]\left[\begin{array}{l}
x_{(k-1)} \\
y_{(k-1)} \\
v_{x_{(k-1)}} \\
v_{y_{(k-1)}}
\end{array}\right]+w_{(k-1)}} \\
& {\left[\begin{array}{l}
z_{1(k)} \\
z_{2(k)}
\end{array}\right]=\left[\begin{array}{llll}
1 & 0 & 0 & 0 \\
0 & 1 & 0 & 0
\end{array}\right]\left[\begin{array}{l}
x_{(k)} \\
y_{(k)} \\
v_{x_{(k)}} \\
v_{y_{(k)}}
\end{array}\right]+v_{(k)}}
\end{aligned}
$$

Sehingga bentuk umum (2) dan (3) menjadi:

$$
\begin{aligned}
& \hat{x}=A x+w \\
& \hat{y}=H \hat{x}+v
\end{aligned}
$$

Kalman filter merupakan algoritma adaptif dengan menggunakan noise dalam melakukan estimasi. Kalman filter terdiri dari 2 proses yaitu prediksi dan koreksi. Proses prediksi terdiri dari penentuan state dan penentuan error kovarian. Penentuan state ditunjukkan sebagai 


$$
\hat{x}_{(k)}=A x_{(k-1)}+B u_{k}
$$

dan penentuan error kovarian sebagai

$$
P_{(\mathrm{k})}^{-}=A P_{(\mathrm{k}-1\}} A^{T}+Q P_{(\mathrm{k})}^{-}=A P_{(\mathrm{k}-1\}} A^{T}+Q
$$

Proses koreksi terdiri dari penentuan gain, state dan penentuan error kovarian. Penentuan gain ditunjukkan sebagai:

$$
K_{k}=P_{k}^{-} H^{T}\left(H P_{k}^{-} H^{T}+R\right)^{-1} K_{k}=P_{k}^{-} H^{T}\left(H P_{k}^{-} H^{T}+R\right)^{-1}
$$

Penentuan state ditunjukan sebagai:

$$
\hat{x}_{k}=\hat{x}_{k}^{-}+K_{k}\left(z_{k}-H \hat{x}_{k}^{-}\right) \hat{x}_{k}=\hat{x}_{k}^{-}+K_{k}\left(z_{k}-H \hat{x}_{k}^{-}\right)
$$

Penentuan error kovarian sebagai:

$$
P_{k}=P_{k}^{-}-K_{k} H P_{k}^{-} P_{k}=P_{k}^{-}-K_{k} H P_{k}^{-}
$$

Koordinat sistem downlink digunakan sebagai acuan sistem maka

$$
\begin{aligned}
& x=\text { Lat }_{\text {obj }}-\text { lat }_{\text {ground }} \\
& y=\text { Long }_{\text {obj }}-\text { Long ground }_{\text {gro }} \\
& z=\text { Alt }_{\text {obj }}-\text { Alt }_{\text {ground }}
\end{aligned}
$$

Obj adalah posisi dari pesawat tanpa awak dan ground adalah posisi dari sistem downlink. Nilai $\mathrm{x}$ adalah selisih dari latitude pesawat tanpa awak dengan lalitude sistem downlink. Sedangkan nilai y adalah selisih dari longitude pesawat tanpa awak dengan longitude sistem downlink. Nilai $\mathrm{z}$ adalah selisih dari altitude pesawat tanpa awak dengan altitude sistem downlink. Nilai latitude, longitude dan altitude berasal dari data GPS yang terpasang. Untuk mengetahui performa dari algoritma adaptif dilakukan sebuah simulasi untuk menguji algoritma adaptif. Dengan menggunakan nilai $\mathrm{x}, \mathrm{y}$ dan $\mathrm{z}$ maka simulasi algoritma adaptif dapat dilakukan.

\section{Hasil Dan Pembahasan}

Langkah pertama yang dilakukan adalah identifikasi sistem dan implementasinya pada algoritma Kalman Filter. Secara umum data data dari sensor dapat dimodelkan sebagai:

$$
\begin{aligned}
z_{x} & =x+w \\
z_{y} & =y+w \\
z_{z} & =z+w z_{z}=z+w \\
z_{x} z_{x}, z_{y} z_{y}{ }_{\text {dan }}{ }^{z_{z} z_{z}} \text { adalah nilai } & x, y x, y \text { dan }^{z z} \text { yang terbaca oleh sensor dengan }
\end{aligned}
$$
adalah noise sensor. Dengan data tersebut, state prediksi menjadi: 
Agus Basukesti, Bangga Dirgantara Adiputra

$$
\hat{x}_{(k)}^{-}=\hat{x}_{(k-1)} \hat{x}_{(k)}^{-}=\hat{x}_{(k-1)}
$$

Dan error kovarian prediksi menjadi

$$
P_{(k)}^{-}=P_{(k-1)} P_{(k)}^{-}=P_{(k-1)}
$$

Setelah mendapatkan nilai state dan error kovarian prediksi, selanjutnya ditentukan koreksi pada state dan error kovarian. Nilai state koreksi menjadi

$$
\hat{x}_{k}=\hat{x}_{k}^{-}+K_{k}\left(z_{k}-\hat{x}_{k}^{-}\right) \hat{x}_{k}=\hat{x}_{k}^{-}+K_{k}\left(z_{k}-\hat{x}_{k}^{-}\right)
$$

$z_{k} z_{k}$ adalah nilai state yang terbaca oleh sensor sedangkan ${ }^{\hat{x}_{k}^{-} \hat{x}_{k}^{-}}$adalah nilai state yang diprediksi sebelumnya. ${ }^{K_{k} K_{k}}$ adalah gain Kalman yang ditentukan dengan:

$$
K_{k}=P_{k}^{-}\left(P_{k}^{-}+R\right)^{-1} K_{k}=P_{k}^{-}\left(P_{k}^{-}+R\right)^{-1}
$$

RR adalah nilai maksimum dari noise yang digunakan. ${ }^{w w}$ adalah noise yang dibangkitkan dengan bilangan acak dengan nilai maksimal ${ }^{R R}$. Setelah nilai state dikoreksi, error kovarian dikoreksi dengan

$$
P_{k}=P_{k}^{-}-K_{k} P_{k}^{-} P_{k}=P_{k}^{-}-K_{k} P_{k}^{-}
$$

Nilai state dan nilai error kovarian yang telah dikoreksi digunakan untuk melakukan prediksi pada tahap selanjutnya. Proses ini digunakan secara terus menerus untuk mendapatkan nilai output yang sesungguhnya dari sensor. Implementasi algoritma dalam simulator adalah sebagai berikut:

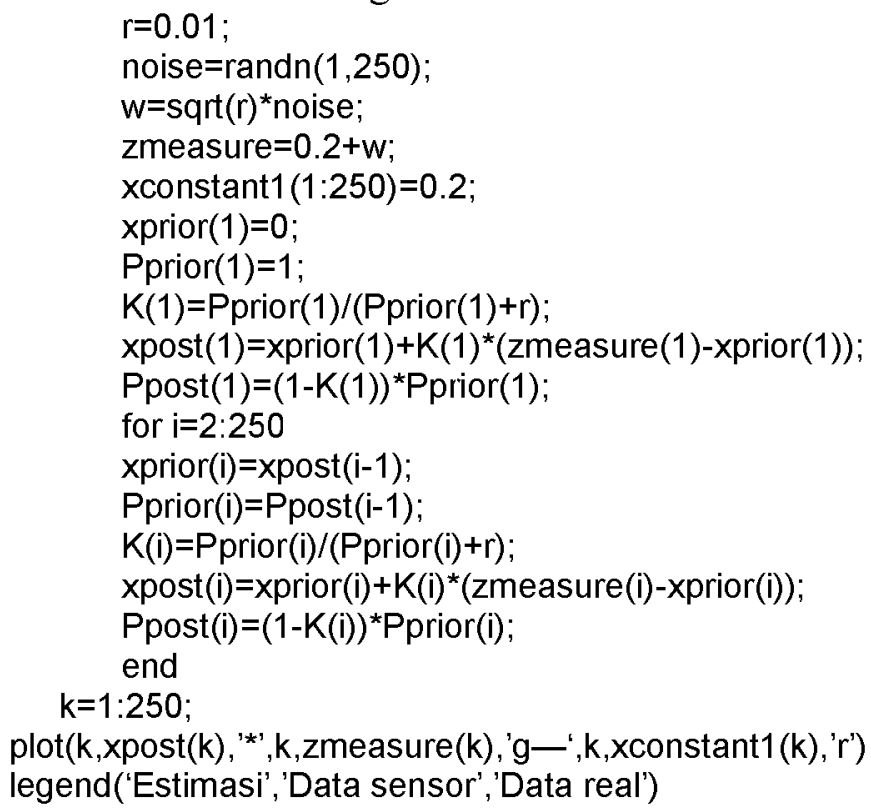


Setelah dilakukan simulasi dapat dilihat bahwa algoritma dapat menentukan nilai sesungguhnya dari sebuah sinyal meskipun sensor memiliki noise

Hasil Simulasi

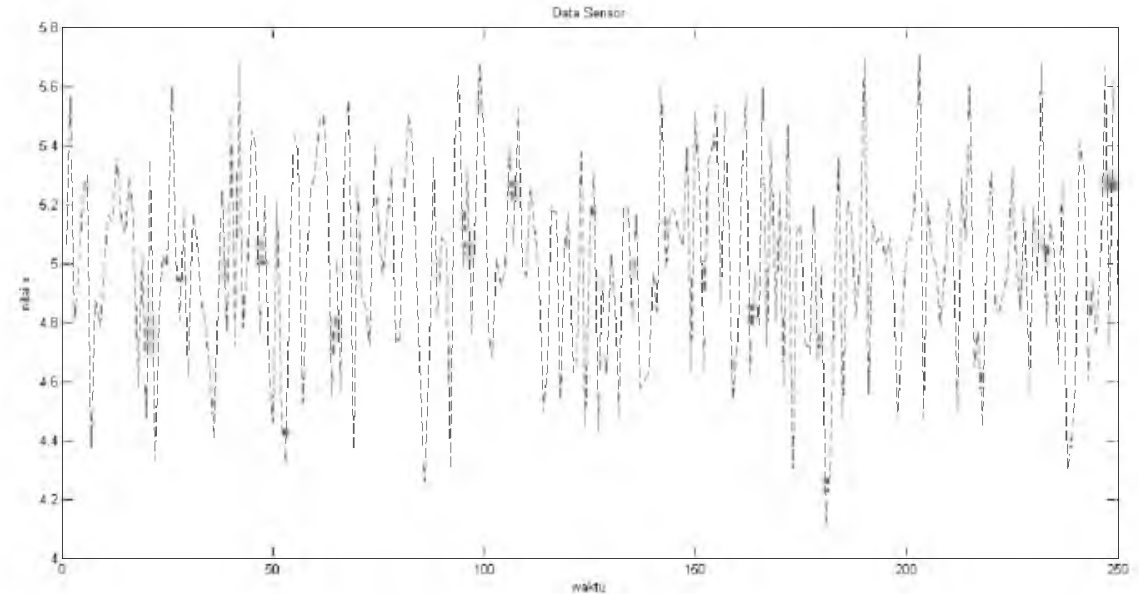

Gambar 1. Data Sensor

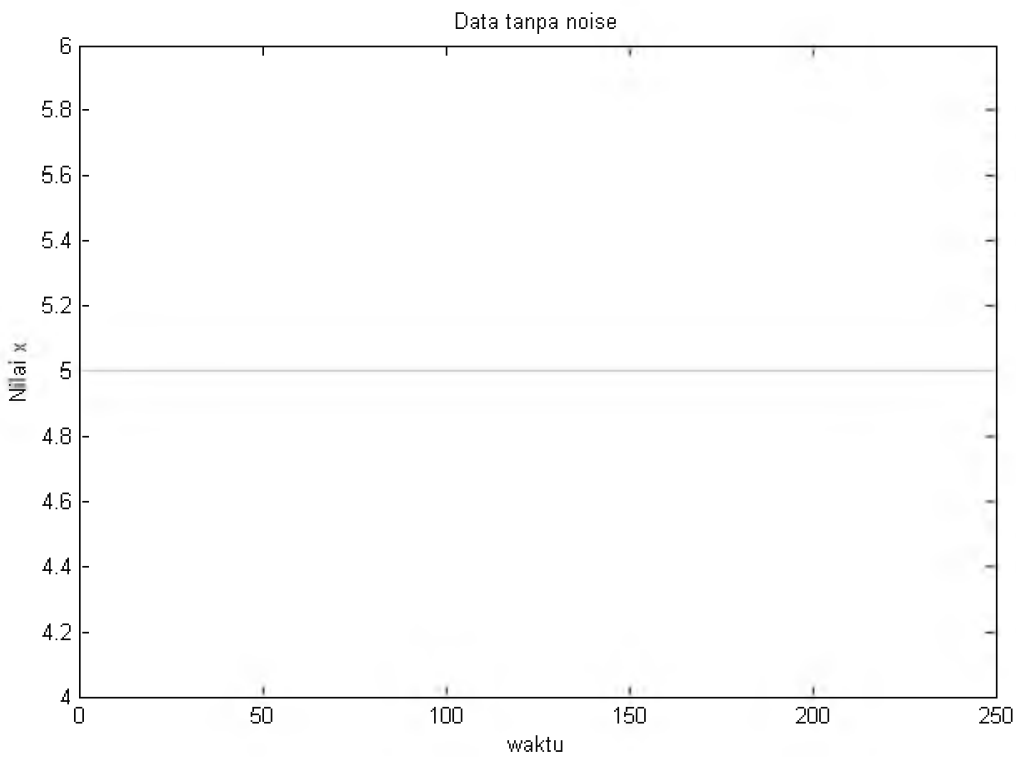

Gambar 2. Data Tanpa Noise 


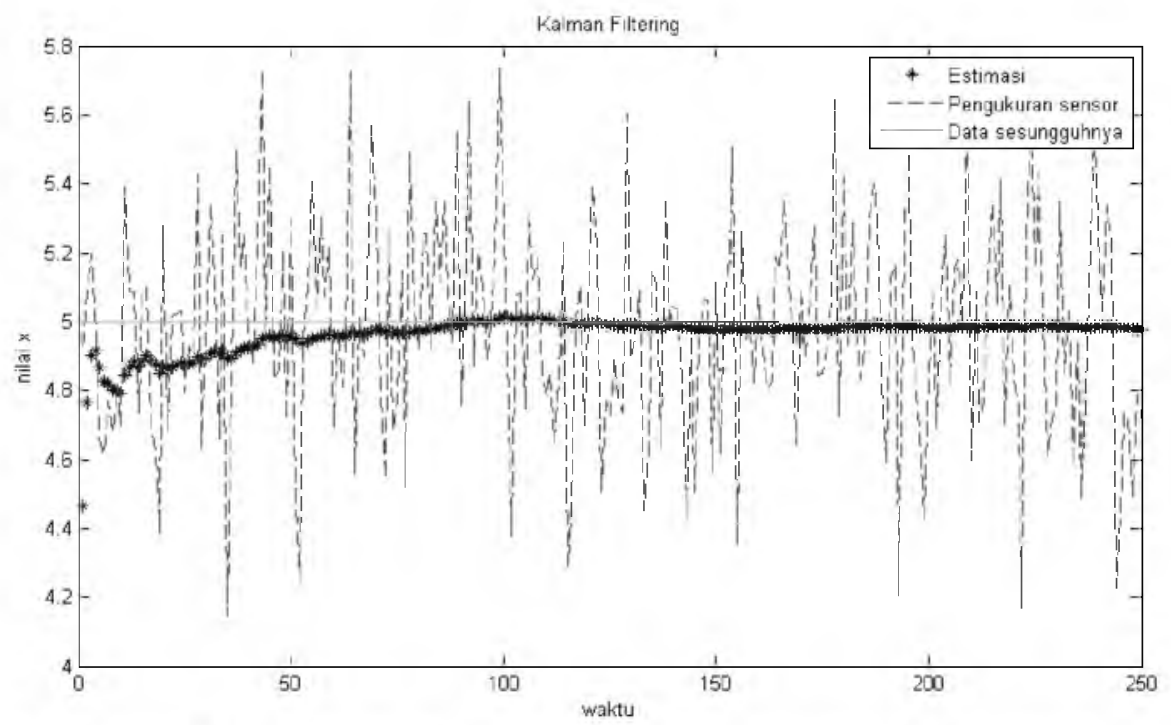

Gambar 3. Perbandingan hasil filter terhadap input sensor dan data sesungguhnya.

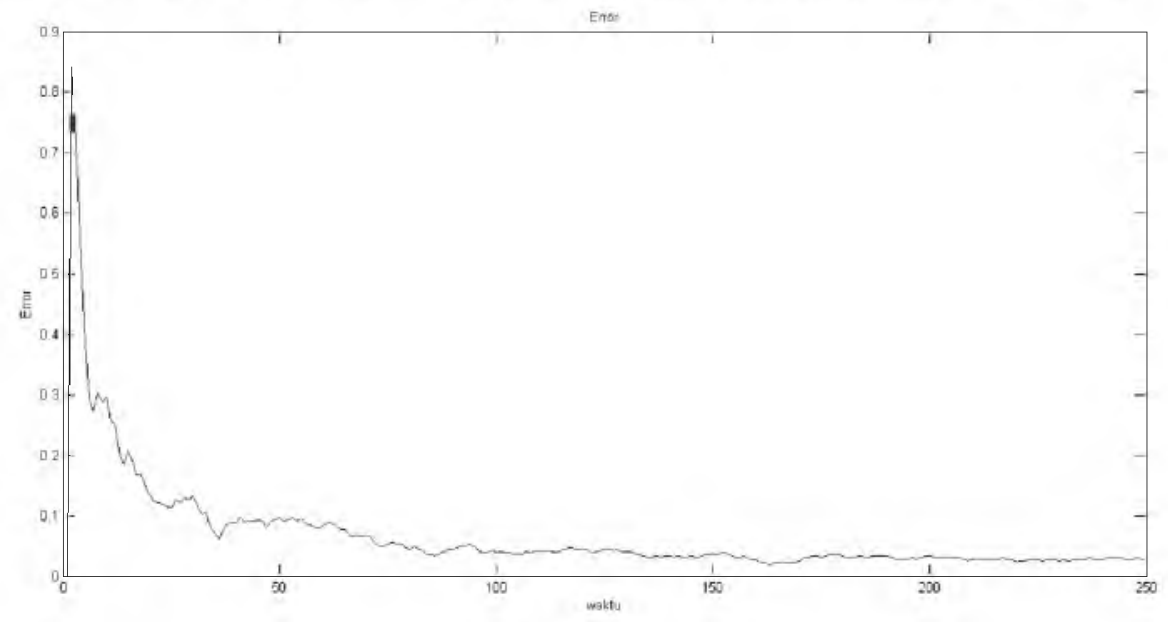

Gambar 4. Error Estimasi

Dari simulasi yang dilakukan dapat disimpulkan bahwa algoritma adaptif yang dipilih dapat mereduksi noise sehingga dapat menghasilkan estimasi yang baik. Dengan demikian algoritma tersebut dapat diimplementasikan ke sistem downlink.

\section{Kesimpulan}

Dari hasil identifikasi dan simulasi yang dilakukan dapat disimpulkan bahwa algoritma adaptif yang dirancang dapat bekerja dengan baik dan perlu diimplementasikan pada sistem downlink yang dirancang. Dari hasil simulasi didapatkan bahwa error dari algoritma memiliki sifat konvergen yaitu semakin lama semakin mengecil. 


\section{Daftar Pustaka}

C. Hide, T. Moore, and M. Smith, "Adaptive Kalman filtering algorithms for integrating GPS and low cost INS," Position Location and Navigation Symposium, 2004. PLANS 2004. pp. 227-233, 2004.

I. M. Taylor and M. A. Labrador, "Improving the energy consumption in mobile phones by filtering noisy GPS fixes with modified Kalman filters," Wireless Communications and Networking Conference (WCNC), 2011 IEEE. pp. 2006-2011, 2011.

J. W. Chaffee and J. S. Abel, "The GPS filtering problem," Position Location and Navigation Symposium, 1992. Record. 500 Years After Columbus - Navigation Challenges of Tomorrow. IEEE PLANS '92., IEEE. pp. 12-20, 1992.

L. Wu, H. Ma, W. Ding, Q. Hu, G. Zhang, and D. Lu, "Study of GPS Data De-Noising Method Based on Wavelet and Kalman Filtering," Circuits, Communications and System (PACCS), 2011 Third Pacific-Asia Conference on. pp. 1-3, 2011.

M. Zahaby, P. Gaonjur, and S. Farajian, "Location tracking in GPS using Kalman Filter through SMS," EUROCON 2009, EUROCON '09. IEEE. pp. 1707-1711, 2009.

S. Yamaguchi and T. Tanaka, "GPS Standard Positioning using Kalman filter," SICE-ICASE, 2006. International Joint Conference. pp. 1351-1354, 2006.

X. Mao, M. Wada, and H. Hashimoto, "Nonlinear filtering algorithms for GPS using pseudorange and Doppler shift measurements," Intelligent Transportation Systems, 2002. Proceedings. The IEEE $5^{\text {th }}$ International Conference on. pp. 914-919, 2002. 
Agus Basukesti, Bangga Dirgantara Adiputra 